J. Clin. Chem. Clin. Biochem.

Vol. 25, 1987, pp. 199-204

(C) 1987 Walter de Gruyter \& Co.

Berlin - New York

\title{
The Comparability of Ethanol Concentrations in Peripheral Blood and Saliva The Phenomenon of Variation in Saliva to Blood Concentration Ratios ${ }^{1}$ )
}

\author{
By R. Haeckel and I. Bucklitsch \\ Institut für Laboratoriumsmedizin (Direktor: Prof. Dr. R. Haeckel), \\ Zentralkrankenhaus St.-Jürgen-Straße, Bremen
}

(Received November 10 1986/February 9, 1987)

Summary: Ethanol appears to reach a higher peak concentration in saliva than in peripheral blood, and to be eliminated from both compartments at different rates. This phenomenon of different elimination rates, which leads to a cross-over of both concentration versus time curves, can be explained by differences in the water content of both body fluids. When the water content is considered, the salivary ethanol concentration parallels the blood level in the elimination phase, more closely in capillary blood than in venous blood.

Equations are derived for the conversion of the ethanol concentration in one to that of the other body fluid.

\section{Introduction}

After its oral intake, ethanol can be detected not only in the blood stream but also in urine, cerebrospinal fluid, breath and saliva. The determination of blood ethanol concentration has been standardised for forensic purposes. Since blood sampling requires the action of a physician, the whole process is considered to be time consuming, with too many persons involved. Therefore, breath analysis has been proposed as an alternative.

Among several disadvantages of breath analysis it has been pointed out that the specimen cannot be stored for repeat analyses, or for the detection of other compounds.

Saliva represents another possible alternative, which can be easily stored. Several authors $(1,2)$ have reported that the salivary concentration of ethanol more or less parallels the blood level in the postresorptive phase with a constant saliva to blood ratio $(3,4)$. This observation, however, was not confirmed by others $(5,6)$.

Because of these conflicting results we have reinvestigated the behaviour of the ethanol concentration in saliva in comparison with that in blood.

\section{Methods}

Saliva was obtained by a standardised technique (7) from healthy persons, by absorption into a dental cotton roll either without or after stimulation of salivary flow by chewing for about 30 seconds. In the stimulation experiments a cotton roll impregnated with about $25 \mathrm{mg}$ citric acid was used. After being soaked with saliva the dental roll was placed in a container, and closed with a plastic stopper. The container fits into a polystyrol tube which is centrifuged for 3 minutes at about $1000 \mathrm{~g}$. During centrifugation the saliva passes from the cotton roll into the lower part of the tube. The container can then be taken out of the tube and the clear saliva be poured out of the tube. Cellular particles are retained at the bottom of the tube in a small sink compartment (fig. 1). The tube and container set, known as salivette, is commercially available from W. Sarstedt (D-5223 Nümbrecht).

The ethanol concentration was determined enzymically according to Frey et al. (8) using testomar-Alkohol Mono from Behringwerke GmbH (D-3550 Marburg, cat. No. OSTI 40). A semiautomated procedure (Eppendorf system 5163 and 6115S from Eppendorf Gerätebau GmbH, D-2000 Hamburg) with an automated sampling device was used. The quality was checked with Fluinorm-Ethanol (cat. No. OSGA 10) and FluinormEthanol U (cat. No. OSGD 08) from Behringwerke. The between-days imprecision was: $\overline{\mathrm{x}}=23.9, \mathrm{~s}=0.52$, coefficient of variation $=2.2 \%, n=17$. The ethanol concentration in $\mathrm{g} / \mathrm{l}$ was divided by $1.056(9,10)$ to obtain $\mathrm{g} / \mathrm{kg}(\%)$-values. All determinations were performed after storage of the specimens overnight at $4{ }^{\circ} \mathrm{C}$. Ethanol has been found to be stable in saliva for at least 21 days at $4^{\circ} \mathrm{C}(11)$.

1) Already presented in part in this J. (1985) 23, 590 . 


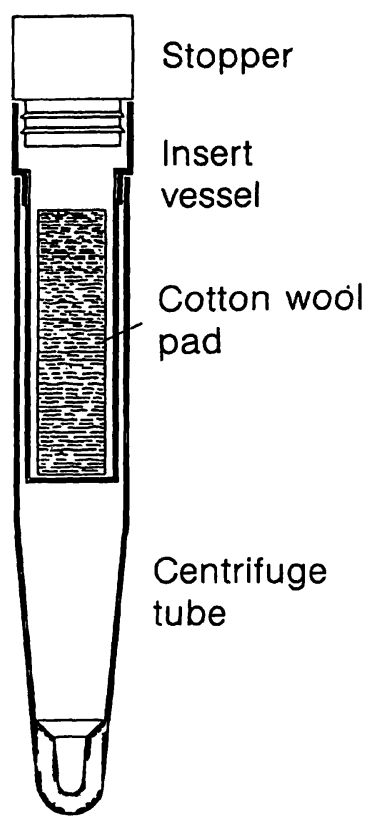

Fig. 1. Salivette for saliva sampling.

Saliva and blood were deproteinised with $0.33 \mathrm{~mol} / 1$ perchloric acid. Blood was collected from butterfly cannulas inserted into a cubital vein or from finger tips with heparinised $20 \mu \mathrm{l}$ glass capillaries which were placed into $1.5 \mathrm{ml}$ reaction cups filled with $500 \mu \mathrm{l}$ perchloric acid. Under these conditions the volume displacement effect was about $1.0 \%^{2}$ ) and it was neglected for the further calculation of the ethanol concentration in blood. The butterfly was rinsed with a physiological sodium chloride solution. Before each sampling about $4 \mathrm{ml}$ were aspirated and discarded.

The ethanol concentration in the aqueous compartment of blood was calculated by multiplying the blood concentration in $\mathrm{g} / \mathrm{kg}$ by

$$
\frac{1000}{\text { water in g per kg blood }} \text {. }
$$

The water content of blood was determined by weighing 40 or $100 \mu \mathrm{l}$ before and after drying at $120^{\circ} \mathrm{C}$ overnight. Blood samples were taken from several individuals at the beginning, middle and end of the ethanol uptake experiment. The mean water content was found to be $785 \mathrm{~g} / \mathrm{kg}$ (range $773.5-796.7$, $\mathrm{n}=36$ ).

For kinetic studies the probands $(58-84 \mathrm{~kg})$ drank $600 \mathrm{ml}$ wine during 15 minutes (about $37.1 \mathrm{~g}$ ethanol).

The possible adsorption of ethanol to the salivette was tested with an ethanol standard solution from E. Merck AG (D-6100 Darmstadt, cat. No. 8988 and 8991): $2 \mathrm{ml}$ were allowed to soak into a cotton roll which was then replaced in a salivette. After a $24 \mathrm{~h}$ storage at $4{ }^{\circ} \mathrm{C}$ the salivette was centrifuged for $3 \mathrm{~min}$ at $1000 \mathrm{~g}$ to remove the control serum from the cotton roll. The ethanol concentration was then determined in the treated sample and in another portion of the same control serum, which had been kept in the primary container for $24 \mathrm{~h}$ at $4^{\circ} \mathrm{C}$.

This experiment was repeated 5 times in 3 days $(n=15)$ and the results were subjected to a paired t-test. A significant adsorption effect of ethanol was not detected in the absence or the presence of citric acid.

2) $\frac{0.81 \cdot 0.02+0.5}{0.52}=0.99 ; 0.81 \mathrm{ml}$ water per ml blood (9), $0.02 \mathrm{ml}$ volume of glass capillaries,

$0.5 \mathrm{ml}$ volume of perchloric acid.

\section{Results}

The influence of salivary flow rate on the ethanol concentration was investigated. "Unstimulated" saliva was obtained by placing cotton rolls of salivettes under the resting tongue without chewing activities. Then the probands were asked: to chew on another cotton roll impregnated with citric acid for about 1-2 minutes ("stimulated" saliva). The ethanol concentration determined at various times after the oral uptake of about $600 \mathrm{ml}$ wine was almost identical in stimulated and unstimulated saliva (fig. 2). However, a slight crossing over of the two curves was detected.

In figure 3 salivary concentrations are compared with blood levels of ethanol in the postresorptive phase from several healthy persons. A good correlation was found. The average saliva/plasma ratio was 1.032 . Similar results have been published by Jones (3). However, this author observed a greater difference

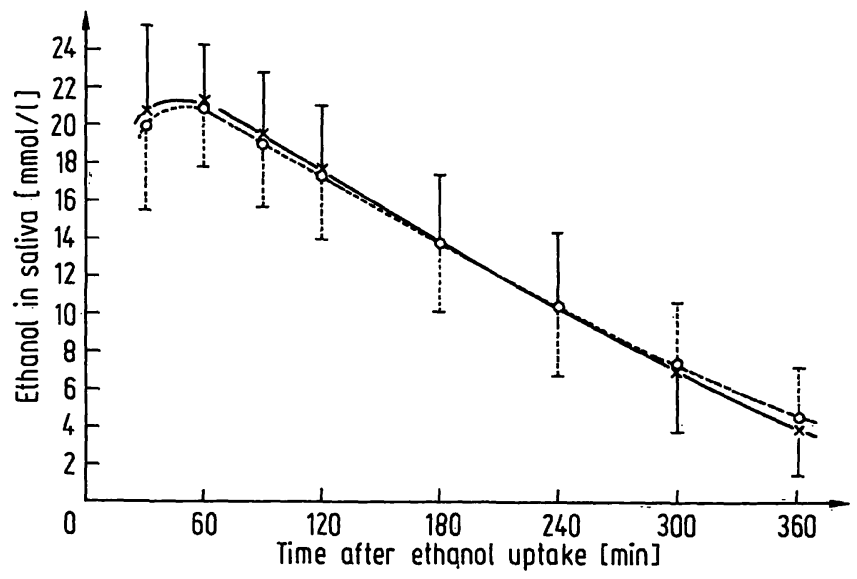

Fig. 2. The concentration of salivary ethanol after sampling with dental cotton rolls either impregnated with citric acid $(+-+)$ or untreated $(0 \cdots 0)$.

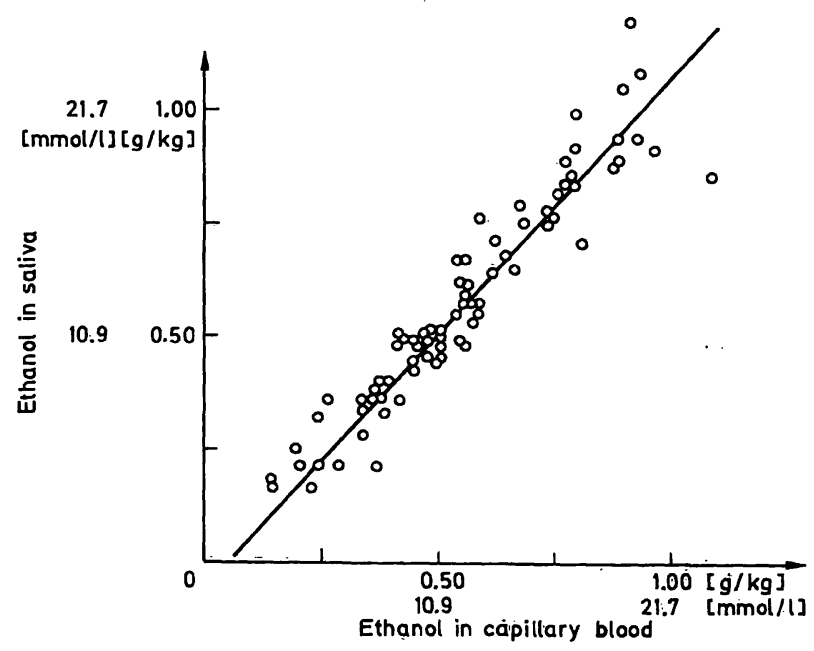

Fig. 3. Ethanol concentration in saliva and capillary blood taken at random times during the elimination phase. The oral uptake of ethanol was not standardised. Standardised principal component: $\dot{y}=1.124 x-0.051$; $\overline{\mathrm{x}}=0.556, \mathrm{~s}=0.214 ; \overline{\mathrm{y}}=0.5 \mathrm{~T} 74, \mathrm{~s}=0.241 ; \mathrm{n}=76$. 
with mixed saliva. To find an explanation for this discrepancy we compared the ethanol concentration during the resorption and elimination phase in capillary and venous blood with that in saliva from 11 individuals.

In all cases a cross-over between the capillary and venous blood curves occurred in the resorption phase. During the ethanol elimination period both curves were almost parallel. In figure 4 the mean values from several probands are shown. Both curves crossed the saliva curve during the elimination phase. This crossover was obtained irrespective of whether the ethanol was consumed with breakfast or after a 6 hour fast and without further food intake (not shown).

Ethanol, being hydrophilic, diffuses primarily into the aqueous compartment of blood. Therefore, the ethanol concentration in the water phase should be almost identical with the ethanol concentration in saliva after a complete diffusion equilibrium has been reached (12). In figure 5 the water content of capillary

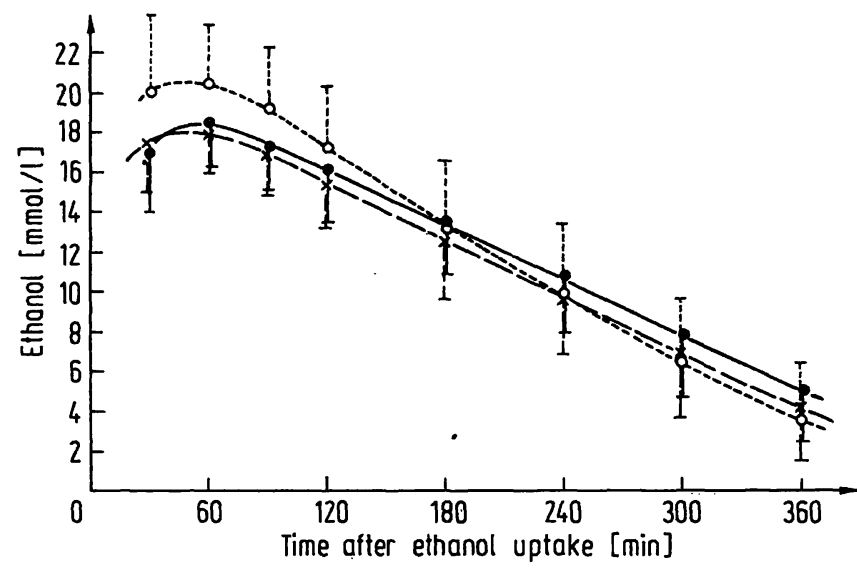

Fig. 4. Ethanol concentration in mixed saliva, capillary blood and venous blood after oral uptake. Vertical bars represent standard deviations $(n=11)$. $\bullet-\bullet$ venous blood, $x---x$ capillary blood, $0---0$ saliva.

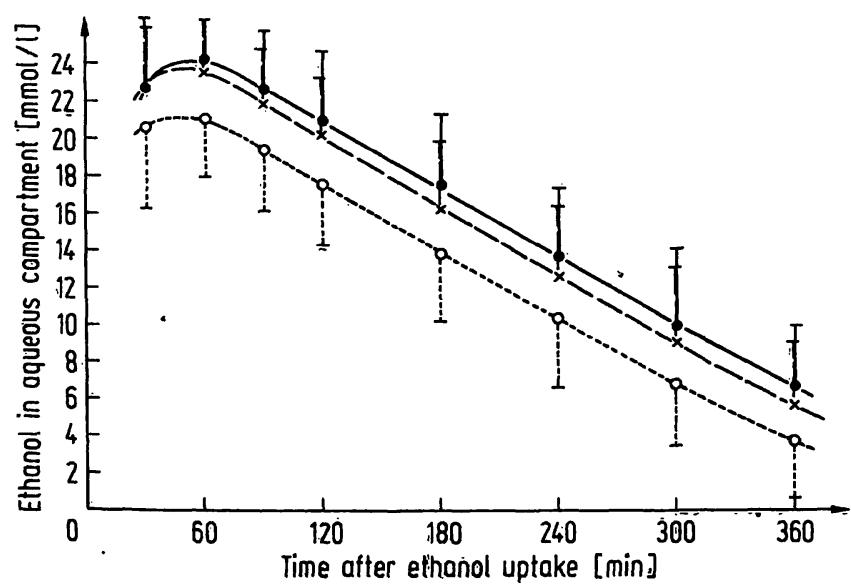

Fig. 5. Ethanol concentration in saliva and in the water phase of capillary and venous blood. The experimental conditions are identical to those reported in the legend to figure 4. and venous blood samples was considered. The blood curves parallel the saliva curve in the elimination phase; the capillary blood curve more exactly than the venous blood curve, which diverges slightly at the end of the experiment.

The difference between the blood and the saliva curves indicated that the diffusion between both compartments is not complete. But it is constant during the elimination phase, in contrast to the saliva/blood ratio (fig. 6 and 7). Therefore, the ethanol concentration in capillary blood (Eq $1 \mathrm{a}$ : $\mathrm{y}$ in $\mathrm{mmol} / \mathrm{l}$ and $\mathrm{Eq} 1 \mathrm{~b}$ : $y$ in $\mathrm{g} / \mathrm{kg}$ ) can be estimated from the concentration in saliva (Eq $1 \mathrm{a}: \mathrm{x}$ in $\mathrm{mmol} / \mathrm{l}$ and $\mathrm{Eq} 1 \mathrm{~b}: \mathrm{x}$ in $\mathrm{g} / \mathrm{l}$ which equals approximately $\mathrm{g} / \mathrm{kg}$ ) using the following equation

$$
\begin{aligned}
& y=(x+2.620) \cdot 0.785 \\
& y=(x+0.073) \cdot 0.785
\end{aligned}
$$

In this equation 0.785 represents the blood water contents, while 2.62 and 0.073 the mean difference of the blood/saliva curve in figure 6 between the 90th and 300 th minute. This mean value was determined as the difference of the intercept of the two regression lines (calculated as the standardised principle component according to l.c. (13)) with the ordinate (fig. 5).

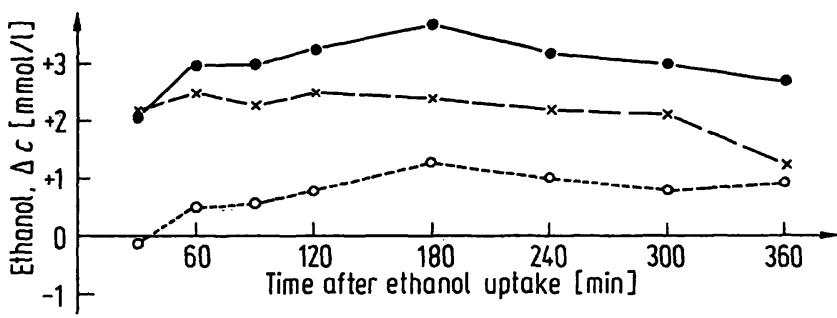

Fig. 6. The mean differences $(n=10)$ between the ethanol concentration determined in the aqueous compartment of capillary $(+-.++)$ or cubital vein blood $(0-\theta)$ and in mixed saliva. $0-0$ ethanol concentration in venous minus capillary blood.

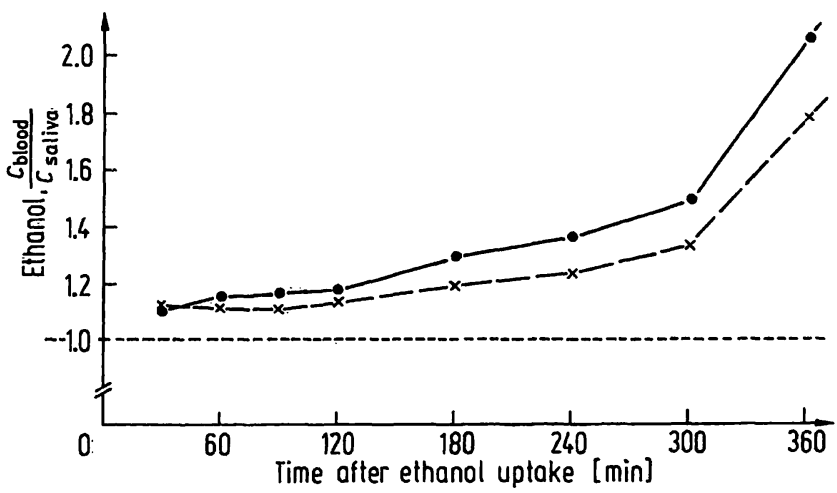

Fig. 7. The mean blood/saliva ratio $(n=11)$ of the ethanol concentration. $+\cdots+$ capillary blood/saliva, - - venous blood/saliva. 
Similarly the ethanol concentration in cubital vein blood can be derived from saliva values (Eq $2 \mathrm{a}$ in $\mathrm{mmol} / \mathrm{l}$ and $\mathrm{Eq} 2 \mathrm{~b}$ in $\mathrm{g} / \mathrm{kg}$ ):

$$
\begin{aligned}
& y=(x+3.400) \cdot 0.785 \\
& y=(x+0.115) \cdot 0.785
\end{aligned}
$$

The ethanol concentration in capillary blood (fig. 8) and in cubital vein blood (fig. 9) calculated from saliva values were compared with those directly measured in the blood samples. The correlation was as good as that between the analytical values from capillary and venous blood (fig. 10).

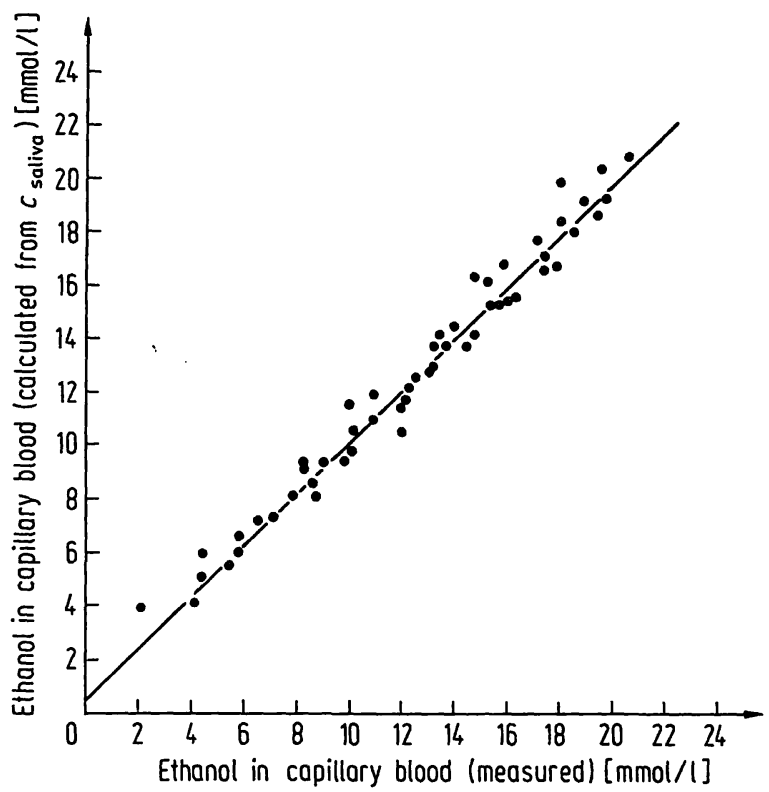

Fig. 8. Comparison between the ethanol concentration in capillary blood analytically determined and derived from saliva values according to equation $1 \mathrm{a}$. Standardised principle component: $\mathrm{y}=0.96 \mathrm{x}+0.59 ; \overline{\mathrm{x}}=12.59$, $\mathrm{s}=4.71 ; \bar{y}=12.75, \mathrm{~s}=4.54 ; \mathrm{n}=54, \mathrm{r}=0.98$.

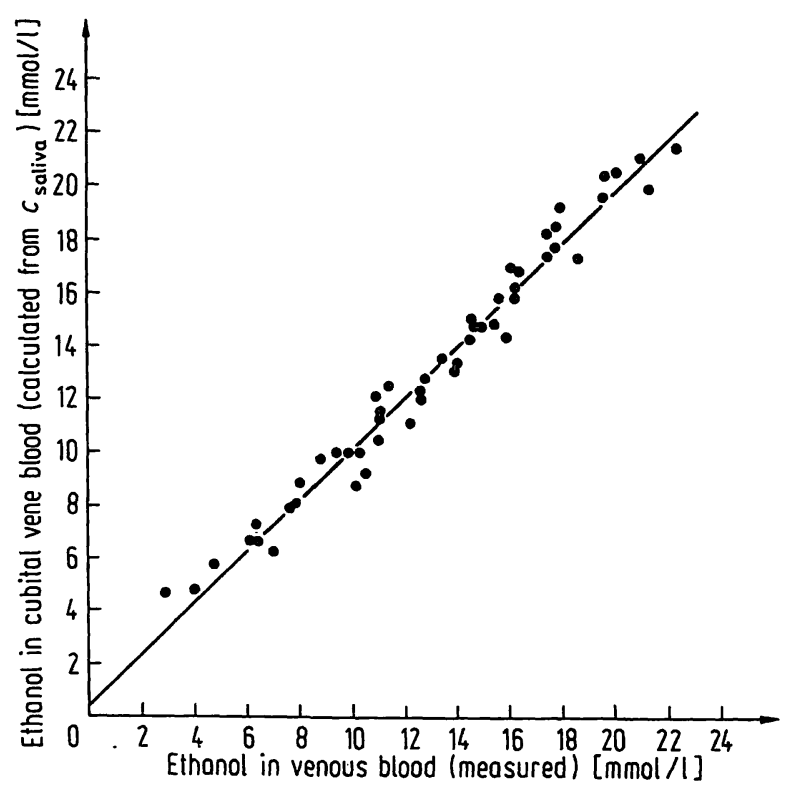

Fig. 9. Comparison between the ethanol concentration in cubital vein blood analytically determined and derived from saliva values according to equation $2 \mathrm{a}$. Standardised principle component: $\mathrm{y}=0.96 \mathrm{x}+0.48 ; \overline{\mathrm{x}}=13.26$ $s=4.73 ; \bar{y}=13.31, s=4.57 ; n=53, r=0.98$.

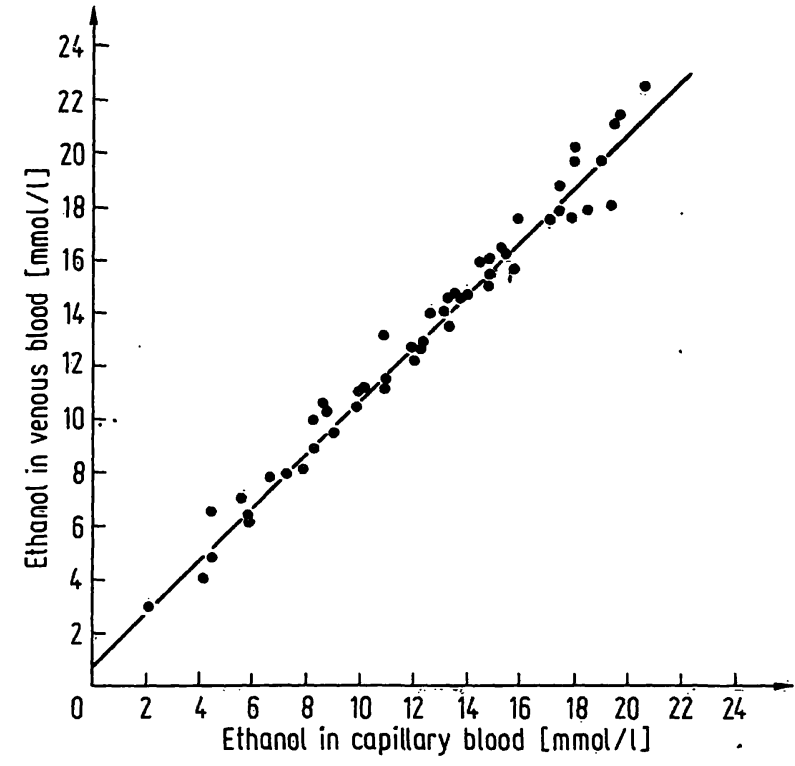

Fig. 10. Comparison between the ethanol concentration analytically determined in capillary and venous blood. Standardised principle component: $y=0.99 x+0.78$; $\overline{\mathrm{x}}=12.49, \mathrm{~s}=4.69 ; \overline{\mathrm{y}}=13.27, \mathrm{~s}=4.68 ; \mathrm{n}=54$, $\mathrm{r}=0.98$.

\section{Discussion}

The excretion of ethanol in saliva was first observed in 1875 by Schmidt (14). Fabre \& Kahane (15) 1938 suggested the use of salivary concentrations for forensic purposes. Gostomzyk et al. (16) showed that the oral clearance is terminated 30 minutes after the last intake of ethanol.

The time-related ethanol concentration curve can be divided into 3 parts: resorption from the intestine dominates the first part (resorption phase); at the peak, resorption and elimination are near equilibrium (distribution phase); in the third phase resorption is complete and elimination effects are dominant (elimination phase).

In all subjects examined a cross-over between saliva and blood ethanol concentration was observed in the resorption and in the elimination phase. The same cross-over was observed in one experiment with dogs by Friedeman et al. (5) and recently by Schulz et al. (6), but only in some human probands during the elimination phase. Similar phenomena have been reported between the venous blood and the breath ethanol concentration (16), and explained by different vascularisation of peripheral and lung tissue.

In the resorption phase the lung receives blood with an ethanol concentration higher than in venous blood from the cubital region. In the elimination phase the resorption is complete, and arterial blood from the heart has a lower ethanol concentration than cubital vein blood in which ethanol rediffuses from peripheral tissues. 
The rapid distribution of ethanol in well vascularised tissue with a high flow-through volume leads to a rapid rise of the cellular ethanol concentration with a relative small arterio-venous difference. In less vascularised tissue the cellular concentration increases more slowly and the arterio-venous difference is larger; therefore, the ethanol concentration is higher in the arterial branch during the resorption phase and in the venous branch during the elimination phase.

All arterial blood has the same ethanol concentration (18). The venous blood concentration depends on the vascularisation of the particular tissue. The well vascularised brain takes up relatively more ethanol with a smaller arterio-venous difference than an extremity. Therefore, the ethanol concentration in the vena jugularis exceeds that in an arm vein during the resorption phase (19). The lung, brain and kidney have relatively larger exchange areas and higher flowthrough volumes than the resting muscular tissue. The salivary glands have a flow-through volume (20) of about $4.0-5.0 \mathrm{ml} \cdot \mathrm{min}^{-1} \cdot \mathrm{g}^{-1}$ which is comparable with that of well vascularised organs (kidney: 4.7, brain: 1.4 , resting skeletal muscle: $0.025 \mathrm{ml}$. $\left.\min ^{-1} \cdot \mathrm{g}^{-1}\right)$.

The ethanol concentration of the arterial branch appears to correlate better with the ethanol concentration in brain cells than with the venous cubital blood. This is supported by 2 findings: the arterio-venous difference is smaller in the jugularis region than in the cubital area (19), and the ethanol concentration rises in the brain tissue faster than in peripheral muscles (19).

The capillary blood is usually considered as a part of the arterial branch. The ethanol concentration was not changed when the blood circulation was activated by warming the finger tips at $42^{\circ} \mathrm{C}$ for 10 minutes in a water bath (not shown). The ethanol concentration in saliva paralleled the capillary blood level more closely than the venous blood concentration. Therefore, it can be concluded that saliva is at least as well suited as venous or capillary blood to reflect the

\section{References.}

1. Abels, J. C. (1936) Proc. Soc. Exper. Biol. Med. 34, 504-505.

2. McColl, K. E. L., Whiting, B., Moore, M. R. \& Goldberg, A. (1974) Clin. Sci. 56, 283-286.

3. Jones, A. W. (1979) Clin. Exp. Pharm. Physiol. 6, 53-59.

4. Jones, A. W. (1979) Clin. Chem. 25, 1394-1398.

5. Friedemann, Th. E., Motel, W. G. \& Necheles, H. (1938) J. Lab. 'Clin. Med. 23, $1007-1014$.

6. Schulz, E., Magerl, H. \& Vock, R. (1986) Blutalkohol 23, 55-63. intoxication state in the elimination phase after the ethanol is completely distributed. This is also demonstrated by the correlation studies (figs. 8-10).

A similar situation is suggested for the ethanol concentration in breath. Heifer (21) pointed out that the ratio of blood ethanol concentration derived from breath analysis to the blood level determined from venous blood varies between 1.05 and 1.40 under various conditions. Furthermore, the time-dependent concentration curves tend to cross each other. Both phenomena can also be explained by the differences in the water content, in analogy to the situation between blood and saliva.

The use of venous blood is well established for forensic purposes. Breath has also been recommended as a substitute for blood, because its sampling is easier and more economical. However, it has several disadvantages $(17,22)$ :

- the distribution relation between air and blood is temperature dependent,

- the influence of breathing: hyperventilation leads to values which are too low (up to $50 \%$ ) and withholding of breath leads to overestimation of the ethanol concentration (up to $+15 \%$ ),

- interference from methylmercaptan in the case of liver diseases,

- reexamination of results is not possible.

Saliva could be another alternative with the advantage that it can be stored in the same way as blood for repeat analyses, and for analysis of other constituents; furthermore, existing methodology is applicable.

It has to be pointed out, however, that the present experiments were performed under standardised conditions. Therefore, further field studies are required to proof the applicability of saliva for forensic purposes. Furthermore, it has to be clarified whether the ethanol concentration determined in saliva can be converted into blood levels as suggested above, or whether it is necessary to establish special borderline values, in order to use saliva for forensic purposes.
7. Haeckel, R., Fink, P. \& Wille, R. (1985) this j. 23, 590.

8. Frey, H. O., Sirowej, H., Schubert, G., Werle, St. \& Kattermann, R. (1981) Blutalkohol 18, 354-362.

9. Rauen, H. M. (1967) Biochemisches Taschenbuch, Springer Verlag, Berlin, Vol. 2, p. 342.

10. Grüner, O. (1967) Der gerichtsmedizinische Alkoholnachweis, C. Heymanns Verlag, Köln, p. 165.

11. Jones, A. W. (1979) Scand. J. Clin. Lab. Invest. 39, 199-203.

12. Gostomzyk, J. G. \& Grüner, O. (1957) Dtsch. Z. Ges. Gerichtl. Med. 46, 53. 
13. Feldmann, U., Schneider, B., Klinkers, H. \& Haeckel, R. (1981) J. Clin. Chem. Clin. Biochem. 19, 121-137.

14. Schmidt, A. (1875) Zbl. Med. Wiss. 13, 371

15. Fabre, R. \& Kahane, E. (1938) J. Pharmacol. 27, 426.

16. Gostomzyk, J. G., Liebhardt, E. \& Henn, R. (1968) Blutalkohol 4, 239-242.

17. Heifer, U. (1986) Blutalkohol 23, 229-238.

18. Payne, J. P., Hill, D. W. \& King, N. W. (1966) Brit. Med. J. I, 196-202.
19. Gostomzyk, J. G. \& Streffer, Ch. (1969) Blutalkohol 5, $211-224$.

20. Melander, S. \& Johanssion, B. (1968) Pharmacol. Rev. 20 , 117-196.

21. Heifer, U. (1983) Blutalkohol 20, 131-143.

22. Grüner, O. (1985) Die Atemalkoholprobe, C. HeymannsVerlag, Köln, pp. 1-138.

Prof. Dr. R. Haeckel

Zentralkrankenhaus

St.-Jürgen-Straße

D-2800 Bremen 1 